\title{
Lipid droplet-associated proteins in atherosclerosis (Review)
}

\author{
JANEESH PLAKKALAYYAPPAN, ANTONI PAUL and YOUNG-HWA GOO \\ Center for Cardovascular Sciences, Albany Medical College, Albany, NY 12208, USA
}

Received August 28, 2015; Accepted January 29, 2016

DOI: $10.3892 / \mathrm{mmr} .2016 .5099$

\begin{abstract}
Accumulation of atherosclerotic plaques in arterial walls leads to major cardiovascular diseases and stroke. Macrophages/foam cells are central components of atherosclerotic plaques, which populate the arterial wall in order to remove harmful modified low-density lipoprotein (LDL) particles, resulting in the accumulation of lipids, mostly LDL-derived cholesterol ester, in cytosolic lipid droplets (LDs). At present, LDs are recognized as dynamic organelles that govern cellular metabolic processes. LDs consist of an inner core of neutral lipids surrounded by a monolayer of phospholipids and free cholesterol, and contain LD-associated proteins (LDAPs) that regulate LD functions. Foam cells are characterized by an aberrant accumulation of cytosolic LDs, and are considered a hallmark of atherosclerotic lesions through all stages of development. Previous studies have investigated the mechanisms underlying foam cell formation, aiming to discover therapeutic strategies that target foam cells and intervene against atherosclerosis. It is well established that LDAPs have a major role in the pathogenesis of metabolic diseases caused by dysfunction of lipid metabolism, and several studies have linked LDAPs to the development of atherosclerosis. In this review, several foam cell-targeting pathways have been described, with an emphasis on the role of LDAPs in cholesterol mobilization from macrophages. In addition, the potential of LDAPs as therapeutic targets to prevent the progression and/or facilitate the regression of the disease has been discussed.
\end{abstract}

\section{Contents}

1. Introduction

2. Lipid droplets

3. Lipid droplet-associated proteins

4. Cholesterol trafficking in macrophages

5. Approaches to target foam cells

6. Conclusion

Correspondence to: Dr Young-Hwa Goo, Center for Cardovascular Sciences, Albany Medical College, 47 New Scotland Avenue, Albany, NY 12208, USA

E-mail: gooy@mail.amc.edu

Key words: atherosclerosis, cholesterol, foam cell, lipid droplet, lipid droplet-associated proteins, macrophage

\section{Introduction}

On average, every $34 \mathrm{sec}$ someone in the United States suffers from a coronary event, and every $40 \mathrm{sec}$ someone has a stroke (1). Cardiovascular disease and stroke are pathologies associated with the development of atherosclerosis, a chronic inflammatory process that affects the walls of large- and medium-sized arteries. The systemic risk factors associated with a higher prevalence of atherosclerosis-related diseases include dyslipidemia, hypertension, chronic kidney disease, metabolic syndrome and diabetes (1). Unstable plaques may rupture and block the bloodstream, ultimately leading to myocardial infarction or stroke. Atherosclerotic plaques consist of fatty materials, predominantly cholesterol; necrotic cores; calcified regions; and various types of cells, including smooth muscle cells, endothelial cells, immune cells, monocytes and foam cells. Among these cells, lipid-laden macrophages, which are commonly known as foam cells, are central components of the plaques, which have an important role in the process of atherosclerotic plaque development from the early to late stages.

According to the 'response to injury' theory by Ross et al $(2,3)$, atherosclerosis is initiated by maladaptation of the blood vessel to endothelial cell damage. Injured endothelial cells produce adhesion molecules, which cause monocytes and T lymphocytes to adhere to endothelial cells and migrate to the subendothelial space $(2,3)$. However, later observations have indicated that endothelial injury is not a common feature, and uninjured endothelial cells are actually more common in developing plaques (4). The alternative 'response to retention' hypothesis, postulated by Williams and Tabas (4), proposes that atherogenesis is initiated without endothelial denudation. Low-density lipoprotein (LDL) that enters the intimal space is retained by the subendothelial extracellular matrix molecules, predominantly proteoglycans. Proteoglycan-bound LDL aggregates and is prone to undergo several modifications. In particular, LDL binding to proteoglycans increases susceptibility of LDL to oxidation. Subsequently, oxidized LDL (oxLDL) triggers the synthesis of monocyte chemoattractant protein (MCP-1) by endothelial and smooth muscle cells, and oxLDL is also directly chemoattractive to monocytes (4). Therefore, the final outcome of both hypotheses is that monocytes migrate to the arterial wall and differentiate into arterial macrophages, which take-up oxLDL to become foam cells.

Following endocytosis of oxLDL by macrophages, the cholesterol ester (CE) carried by these particles is hydrolyzed 
to free cholesterol (FC) in the lysosomes, which is subsequently released into the cytosol. Elevated FC levels in macrophages due to uncontrolled LDL uptake can cause membrane damage and cytotoxicity (5). However, toxicity can be prevented by increasing FC efflux to high-density lipoprotein (HDL), or by esterifying $\mathrm{FC}$ to $\mathrm{CE}$, which is subsequently stored in the core of cytoplasmic lipid droplets (LDs) (6) (Fig. 1). As a result of $\mathrm{LD}$ accumulation in the cytosol, macrophages form 'foamy' looking shapes, hence their alternative name, foam cells. While this mechanism may initially be protective, the overwhelming accumulation of foam cells caused by unfettered LDL uptake at the arterial wall results in inflammation and necrosis. Therefore, foam cells have been the object of extensive research efforts aiming to identify novel therapeutic strategies against atherosclerosis. In this review, the general mechanisms of foam cell formation are described, genes associated with LDs and their roles in atherosclerotic development are investigated, and the prospect of targeting foam cells to prevent and/or intervene against atherosclerosis is discussed.

\section{Lipid droplets}

LDs are fat depots found in all eukaryotic cells (7). In mammalian adipocytes, LDs reserve large amounts of lipid to provide energy in the event of scarcity; therefore, the LD was initially considered to be a mere fat reservoir. However, numerous studies have demonstrated that LDs are not only lipid reservoirs but also dynamic organelles that provide lipids for metabolic processes, membrane synthesis, cell signaling and intracellular vesicle trafficking (8-10). In non-adipocytes, LDs protect cells from cytotoxicity caused by a surplus of free fatty acids or FC by storing neutral lipid esters in the cytosol $(11,12)$. However, the excessive storage of lipids in cells is closely associated with metabolic diseases, including obesity, diabetes, fatty liver disease and atherosclerosis (13).

LDs consist of a phospholipid monolayer, lipid droplet-associated proteins (LDAPs), and an inner core of neutral lipids, including triacylglycerol (TAG), sterol esters, retinyl esters, waxes and ether lipids (7,14). A lipidomic study previously revealed that LDs are complexes that contain $>160$ species of phospholipid. The most abundant phospholipid is phosphatidylcholine, followed by phosphatidylethanolamine, phosphatidylinositol and ether-linked phosphatidlycholine (14). The composition of neutral lipids in the core of LDs varies in different cell types. For example, yeast cells contain almost an equal proportion of TAG and CE, whereas adipocytes contain mostly TAG; however, macrophages/foam cells contain mostly CE that originates from LDL (14). In eukaryotes, the prevalent theory for LD biogenesis is that LDs bud off the endoplasmic reticulum (ER), where the majority of enzymes for neutral lipid synthesis are located, including acyl-CoA:cholesterol acyltransferase (ACAT) for sterol esters and acyl-CoA:diacylglycerol acyltransferases for TAG $(15,16)$. Following synthesis of neutral lipids within the interspace of the lipid bilayer of the ER membrane, lipids are enclosed by a monolayer of phospholipids, which originates from the cytoplasmic leaflet (17-20). The newly formed LDs increase in size by incorporating lipids that are synthesized in situ by enzymes localized at the LD surface, or by the fission of pre-existing LDs $(7,21)$.

\section{Lipid droplet-associated proteins}

LDAPs are usually located at the surface of LDs and have an important role in the formation and degradation of LDs (22). Proteomic analyses on LD fractions of lipid-loaded cells have identified numerous LDAPs $(23,24)$. Relatively well-characterized LDAPs include members of the perilipin, ADFP and Tip47 (PAT), and cell death-inducing DNA fragmentation factor-like effector (CIDE) families. In mammals, the PAT family comprises five members: Perilipin 1 (PLIN1), Perilipin 2 (PLIN2/adipophilin/adipose differentiation-related protein/ADFP), Perilipin 3 (PLIN3/Tip47), Perilipin 4 (PLIN4/S3-12), and Perilipin 5 (PLIN5/lipid storage droplet protein 5/myocardial lipid droplet protein/OXPAT/PAT1) (25). The CIDE family comprises three members: CIDEA, CIDEB and CIDEC (human)/fat-specific protein of $27 \mathrm{kDa}$ (mouse). While all cells have the ability to accumulate LDs, the expression of LDAPs varies depending on cell and tissue type. Therefore, different LDAPs are expected to replace the function of others based on their expression pattern. PLIN1 was the first LDAP to be identified (26), and is highly expressed in white and brown adipose tissues, and steroidogenic cells $(26,27)$. In addition, PLIN1 is expressed in detectable amounts in macrophages (28); however, its expression in mouse macrophages remains controversial (29). Four splicing variants of PLIN1 have been identified, namely perilipin A-D $(26,30)$. Perilipin A and B are expressed in adipocytes, whereas the $\mathrm{C}$ and $\mathrm{D}$ isoforms are predominantly expressed in steroidogenic cells. Under non-hydrolytic conditions, interaction of PLIN1 with comparative gene identification-58 (CGI-58) blocks the access of hydrolases to LDs, and protects TAG in LDs against hydrolysis. Under $\beta$-adrenergic receptor activation-induced hydrolytic conditions, both PLIN1 and cytoplasmic hormone sensitive lipase (HSL) are phosphorylated by protein kinase A. Phosphorylated HSL gains access to LDs, whereas phosphorylated PLIN1 dissociates from LDs and releases CGI-58 from the LD surface. Interaction of CGI-58 with adipose triglyceride lipase (ATGL) in the cytoplasm results in translocation of ATGL to LDs, where it primarily hydrolyzes TAG, whereas HSL sequentially breaks down the diacylglycerol generated by ATGL (31,32).

PLIN2 and PLIN3 are ubiquitously expressed $(28,33,34)$. PLIN2 is highly induced by lipid loading, and is expressed in macrophages/foam cells and atherosclerotic plaques $(29,35)$. PLIN2 was initially isolated and characterized during a study on the differentiation of pre-adipocytes into adipocytes (36). Lipid loading increases the transcriptional and post-translational levels of PLIN2, since PLIN2 bound to LDs is protected from degradation by the proteasome pathway $(37,38)$. PLIN2 reduces the affinity of ATGL to LDs, and consequently reduces the degradation of LDs by ATGL (39). A missense polymorphism in PLIN2 (Ser251Pro) has been shown to increase the number of small-sized LDs. The human Pro251 allele was associated with decreased plasma TAG and VLDL concentrations (40).

PLIN3 has been detected on the surface of LDs in HeLa cells using a PLIN3 antibody to track its subcellular localization (41). PLIN3 is involved in the transport of mannose 6-phosphate receptors from endosomes to the trans-Golgi network (42). Unlike PLIN1 and PLIN2, which 


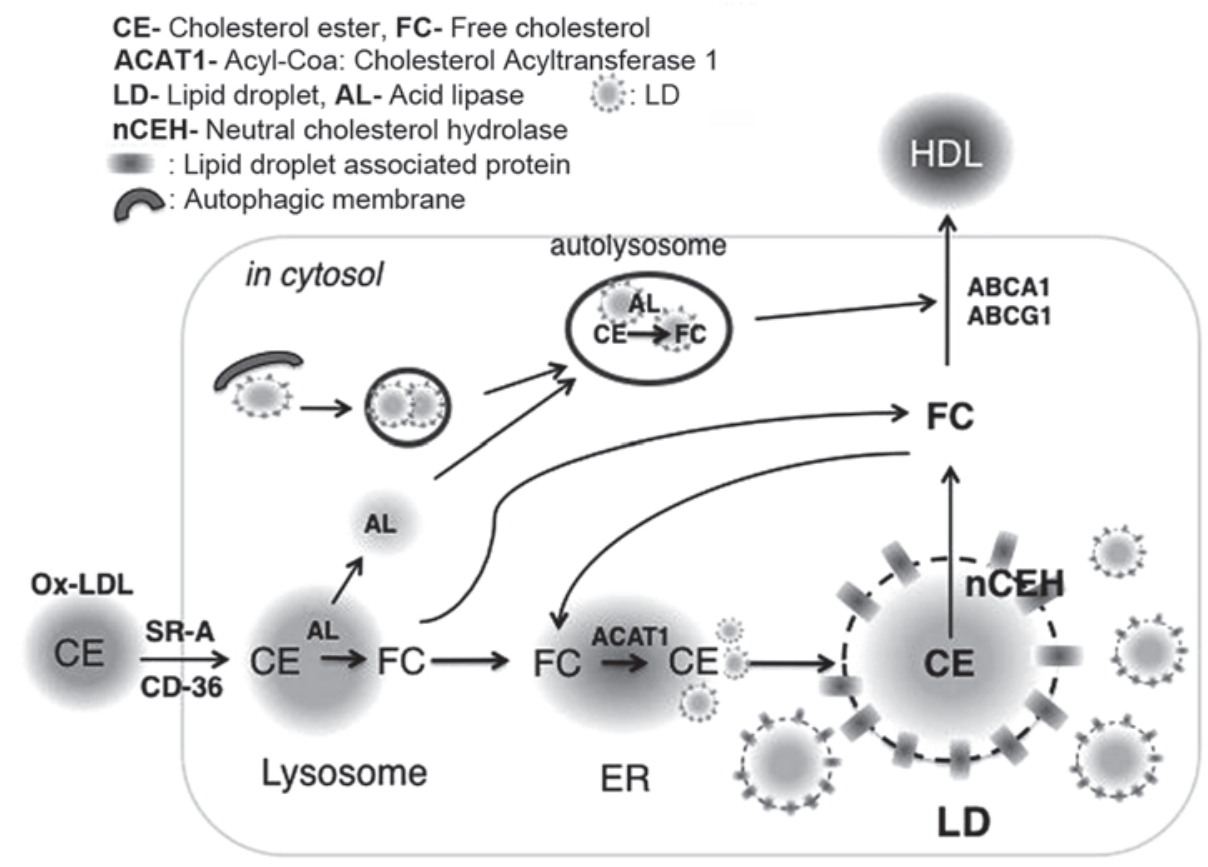

Figure 1. Cholesterol trafficking in macrophages. ABCA1, ATP-binding cassette, sub-family A, member 1; ABCG1, ATP-binding cassette, sub-family G, member 1; ER, endoplasmic reticulum; SR-A, scavenger receptor A; CD-36, cluster of differentiation 36.

are fundamentally associated with LDs, PLIN3 is abundantly found in the cytosol $(43,44)$. Acetylated LDL (acLDL) loading of PLIN2-depleted human THP-1 macrophages was shown to decrease CE levels; however, PLIN3 knockdown reduced TAG levels in acLDL and oleic acid-loaded cells (45). Increased localization of PLIN3 to LDs was observed in PLIN2-depleted THP-1 macrophages, without alterations to PLIN3 expression (29,45). Similarly, Chang et al (46) detected increased PLIN3 localization to LDs in PLIN2-deficient hepatocytes. These results suggest a differential and compensatory role of LDAPs in lipid metabolism even within the same cells. PLIN4 is predominantly detected in white adipose tissue, although lower amounts can be detected in heart and skeletal muscle $(41,47)$. PLIN5 is expressed in heart, brown adipose tissue, liver and skeletal muscle $(34,47)$. A previous study, which used microarrays to identify the expression of LDAPs in oxLDL-loaded THP-1 macrophages, demonstrated that PLIN1 expression was not altered, whereas PLIN2 was increased and PLIN3 was decreased. Furthermore, PLIN4 and PLIN5 were upregulated by oxLDL in THP-1 cells (48).

With distinctive tissue distribution, the three members of the CIDE family are involved in TAG metabolism and their functions are highly associated with metabolic disorders. CIDEA and CIDEB are abundantly expressed in brown adipose tissue and in the liver, respectively $(49,50)$. CIDEC is expressed in white and brown adipose tissues, but not in normal liver tissue $(49,51,52)$. Deletion of each CIDE member in mice resulted in leaner mice due to increased energy expenditure, and was associated with resistance to diet-induced obesity and insulin resistance (53). All three members of the CIDE family have recently been detected in THP-1 macrophages loaded with oxLDL (48). However, the role of CIDEs in cholesterol metabolism and atherosclerotic development has yet to be elucidated.
The predominant form of lipid stored in the LDs of macrophages/foam cells is CE. Whereas PAT and CIDE proteins have central roles in LD metabolism, these proteins do not exert TAG or CE hydrolyzing activities. HSL is the best-characterized CE hydrolase in macrophages $(54,55)$. Despite its strong CE hydrolase activity, the absence of HSL in human macrophages and plaques suggests the possible existence of other CE hydrolase(s) to replace the role of HSL in human atheroma $(23,55)$. A recent proteomic analysis on the LD fraction of Raw 264.7 macrophages identified a novel CE hydrolase, lipid droplet-associated hydrolase (LDAH). Overexpressed LDAH in RAW 264.7 macrophages decreased CE levels by increasing FC efflux (23). LDAH was reported to be ubiquitously expressed; however, it is significantly more abundant in white and brown adipose tissues and in the liver. Notably, LDAH is also highly expressed in both human and mouse macrophages and atherosclerotic lesions (23).

\section{Cholesterol trafficking in macrophages}

In macrophages, oxLDL is notably taken-up via endocytosis mediated by scavenger receptors (SRs), including SR-A and cluster of differentiation 36 (CD36); however, additional mechanisms may mediate oxLDL uptake $(56,57)$. CE derived from oxLDL is hydrolyzed to FC by lysosomal acid lipase (LAL) and is then released into the cytosol. FC in the cytosol is either effluxed by ATP-binding cassette (ABC) transporters, including ABCA1 and ABCG1, or re-esterified by ACAT1 in the ER and stored as CE in cytosolic LDs (Fig. 1). Two LD CE hydrolytic pathways have been reported. In the first pathway, CE in LDs is hydrolyzed to FC by neutral cholesterol ester hydrolases (nCEHs), which associate with LDs. The second pathway involves autophagocytic engulfment of LDs, followed by fusion with lysosomes and CE hydrolysis by LAL (58). FC 
generated from both pathways is effluxed via ABC transporters and transferred to extracellular acceptors for reverse transport to the liver and, ultimately, the feces (Fig. 1).

\section{Approaches to target foam cells}

Due to the central role of foam cells in atherosclerotic development, foam cells have been the target of interventions, in order to identify novel therapeutic strategies. Some of the most significant approaches are described in this review.

Blocking the uptake of oxLDL by knocking down SRs. Native LDL is removed from circulation by the process of endocytosis by LDL receptors (LDLRs); however, modified LDL is recognized and taken-up by SRs $(57,59)$. Among these receptors, SR-A1 and CD36 are responsible for $75-90 \%$ of the degradation of oxLDL in vitro (60). Therefore, blocking SRs may be a promising strategy to ameliorate the development of atherosclerosis. However, studies in SR-A $1^{-/-}$or $\mathrm{CD} 36^{-/-}$ mice with an apolipoprotein E knockout (apoE ${ }^{-/}$) or LDLR knockout (LDLR ${ }^{-/}$) background have exhibited contradictory results. Suzuki et al (61) reported that $\mathrm{SR}-\mathrm{A} 1^{-/-} / \mathrm{apoE}^{-/-}$mice exhibited decreased atherosclerotic lesion development due to reduced cholesterol uptake. However, these mice were more sensitive to infection, since SRs bind a broad range of ligands expressed by bacterial pathogens (61). CD36 ${ }^{-/} / \mathrm{apoE}^{-/-}$mice also exhibited significantly reduced lesion development; however, elevated plasma LDL levels were detected due to loss of LDL uptake (62). In addition, SR-A or CD36 deficiency in macrophages of $\mathrm{LDLR}^{-/}$mice resulted in reduced lesion development (63). Conversely, Moore et al (56) detected increased lesion area in the aortic sinus with abundant macrophages/foam cells in apoE ${ }^{-/}$mice lacking either SR-A1 or CD36, presumably due to alternative LDL uptake mechanisms. Manning-Tobin et al (64) also reported no changes in lesion size and macrophage/foam cell content, but observed reduced inflammatory gene expression and macrophage apoptosis in $\mathrm{SR}-\mathrm{A}^{-/ /} / \mathrm{CD} 36^{-/-} / \mathrm{apoE}^{-/-}$mice. Therefore, the benefit of targeting SRs remains controversial.

Inhibiting re-esterification of FC to $C E\left(A C A T^{--}\right.$mice). Excessive cytoplasmic FC can be re-esterified by ACAT1 in the ER, and the generated $\mathrm{CE}$ can subsequently be stored in LDs (Fig. 2). Since only FC, not CE, can enter efflux pathways, blocking re-esterification of FC to $\mathrm{CE}$ may be considered a promising strategy to inhibit foam cell formation and facilitate cholesterol efflux. Unexpectedly, ACTA $1^{-/}$mice, with either an $\mathrm{LDLR}^{-/-}$or apoE ${ }^{-/-}$background, exhibited increased lesion size with abundant necrotic cores due to macrophage apoptosis as a result of toxicity from excessive FC accumulation in the ER (65-67). Therefore, the therapeutic inhibition of ACAT1 does not appear to be a desirable strategy for the treatment of atherosclerosis.

Blocking LD formation by knocking down LDAPs. Since LDAPs are structurally or enzymatically involved in LD homeostasis, their roles in pathologies associated with dysfunctional lipid metabolism have been extensively studied. As mentioned previously, abundant expression of certain LDAPs in macrophages is closely associated with foam cell formation during atherosclerotic development. Among known LDAPs, PLIN2 is highly expressed in macrophages and its expression is increased by lipid loading, whereas the expression levels of other members of the PAT family remain very low or unchanged $(29,48)$. In line with the role of PLIN2 in TAG accumulation in non-monocytic cells, PLIN2 increased CE accumulation in acLDL-loaded THP-1 macrophage by inhibiting cholesterol efflux (68). In addition, PLIN2 mRNA is highly expressed in human and mouse atherosclerotic plaques compared with healthy areas of the same arteries $(68,69)$. A global approach to identify cholesterol responsive genes in the macrophages of $\mathrm{LDLR}^{-/}$mice loaded with cholesterol in vivo detected increased levels of PLIN2 (35). In agreement with these findings, a significant role for PLIN2 in the development of atherosclerosis was verified by Paul et al (29) using PLIN2 null mice with an apoE ${ }^{-/-}$background. PLIN $2^{-/-} / a_{p o E} E^{-/-}$mice exhibited decreased lesion development with reduced foam cell formation in lesions due to increased FC efflux (29). In addition, contrary to observations made under ACAT1 deficiency, PLIN2 deficiency was well tolerated by the macrophages, thus indicating that PLIN2 may be a safe target for the amelioration of atherosclerotic development (70).

Macrophages/foam cells in the arterial wall generate proinflammatory cytokines. The secretion of these cytokines is an important predictor of atherosclerotic development. The expression levels of proinflammatory cytokines, including tumor necrosis factor- $\alpha, \mathrm{MCP}-1$ and interleukin-6, were increased by PLIN2 overexpression and decreased following knockdown of PLIN2 in THP-1 macrophages loaded with acLDL (71). Regarding the role of PLIN1 in the development of atherosclerosis, contradictory results have been reported. Langlois et al (72) detected increased atherosclerosis in $\mathrm{PLIN1}^{-/-}$mice, whereas Zhao et al (28) reported that global and bone marrow-specific PLIN1 deficiency reduced atherosclerosis. With respect to CIDE proteins, CIDEB has been shown to control hepatic cholesterol homeostasis, and $\mathrm{CIDEB}^{-/-}$mice exhibited lower levels of plasma cholesterol and LDL, and increased hepatic cholesterol levels, due to increased LDLR and ACAT expression (73). These observations raise the possibility that, in addition to a potential role in lipid metabolism in macrophages, CIDE family proteins may have a role in atherogenesis by regulating plasma cholesterol levels.

Increasing CE hydrolysis in LDs. Reverse cholesterol transport (RCT) from arteries involves transfer of cholesterol from macrophages/foam cells to HDL (74). In order to be effluxed, $\mathrm{CE}$ deposited in LDs must be hydrolyzed to $\mathrm{FC}$; therefore, $\mathrm{CE}$ hydrolysis may be considered the first step in RCT $(75,76)$. Since RCT from arteries is considered atheroprotective, enzymes that hydrolyze CE stored in LDs, generally known as nCEHs, may have high therapeutic potential. HSL is an intracellular neutral hydrolase that is able to hydrolyze various esters, including CE in macrophages $(77,78)$. However, HSL knockdown in the bone marrow macrophages of $\mathrm{LDLR}^{-/-}$mice did not induce significant changes in lesion development, indicating the possibility of compensatory mechanisms (79). Unexpectedly, rather than improving atherosclerosis, macrophage-specific expression of transgenic rat HSL in mice with an apoE $E^{-/-}$background accelerated atherosclerosis. This paradoxical effect was not associated with the excessive 


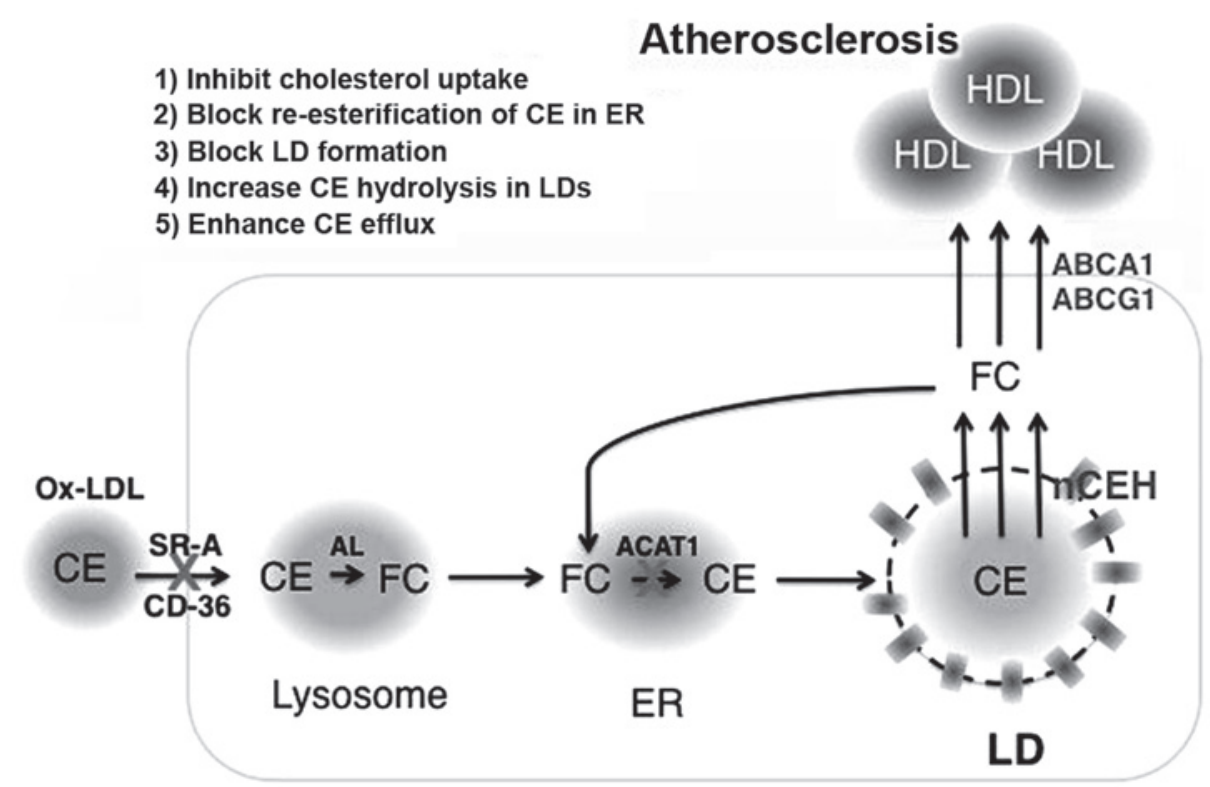

Figure 2. Efforts targeting foam cells to prevent/intervene against atherosclerosis. CE, cholesterol ester; ER, endoplasmic reticulum; LD, lipid droplet; ox-LDL, oxidized low-density lipoprotein; SR-A, scavenger receptor A; CD-36, cluster of differentiation 36; AL, acid lipase; ACAT1, acyl-CoA:cholesterol acyltransferase 1; $\mathrm{nCEH}$, neutral cholesterol hydrolase; ABCA1, ATP-binding cassette, sub-family A, member 1; ABCG1, ATP-binding cassette, sub-family G, member 1; HDL, high-density lipoprotein.

intracellular accumulation of $\mathrm{FC}$, or with larger necrotic core development within the lesions, but was attributed to coupling of effective re-esterification of surplus FC to CE by ACAT1 and to limited efflux by ABC transporters $(77,80)$. Notably, increasing cholesterol acceptors in HSL transgenic mice reduced aortic lesion development (81). However, regardless of its role in mice, HSL is not expressed in human atherosclerotic lesions (23). Therefore, the identity of the $\mathrm{nCEH}(\mathrm{s})$ in human atheroma remains unknown. A possible candidate is LDAH, which is expressed in both human and mouse atherosclerotic lesions, as well as in cultured and primary human and mouse macrophages (23). LDAH overexpression in macrophages has been reported to increase the rate of CE hydrolysis and cholesterol efflux. However, to date, the role of LDAH in genetically engineered mice has yet to be reported (23).

Enhancing cholesterol efflux and acceptors. Although FC can be effluxed by passive diffusion (82), FC from macrophages is mainly effluxed through the $\mathrm{ABC}$ transporters, $\mathrm{ABCA} 1$ and ABCG1 (83). Therefore, inducing expression or activity of $\mathrm{ABC}$ transporters is an attractive strategy to increase RCT from arteries. ABCA1 delivers both $\mathrm{FC}$ and phospholipids to lipid-free or lipid-poor apolipoprotein A-I in order to generate nascent or pre-beta HDL, whereas ABCG1 effluxes FC to HDL particles (84). This gives rise to a synergistic relationship in which the nascent HDL generated by ABCA1-mediated FC efflux serves as substrate for FC efflux by ABCG1. $\mathrm{ABCA}^{-/} / \mathrm{LDLR}^{-/-}$mice exhibit increased atherosclerosis, and human $\mathrm{ABCA} 1$ transgenic mice with an $\mathrm{apoE}^{-/}$background develop markedly smaller and less complex lesions (85). Although plasma HDL levels did not rise, HDL from ABCA1 transgenic mice accepted FC more efficiently than HDL from wild-type mice (86). The role of ABCG1 in atherosclerosis is less clear. The transgenic expression of human ABCG1 in $\mathrm{apoE}^{-/}$mice did not affect lesion development (87). Conversely,
ABCG1 transgenic expression in $\mathrm{LDLR}^{-/}$mice increased atherosclerosis (88). In addition, it has been reported that macrophage-specific deletion of ABCG1 in bone marrow-derived cells decreased lesion development in both apoE ${ }^{-/-}$and $\mathrm{LDLR}^{-1-}$ mice (89), whereas another study observed slightly increased lesion development in $\mathrm{LDLR}^{-/-}$mice with $\mathrm{ABCG1}$ deletion in macrophages (90). Notably, compared with the controversial phenotype of single ABCG1 knockout on the development of atherosclerosis, the double knockout with ABCA1 synergistically increased atherosclerosis development (91).

The expression of $\mathrm{ABCA} 1$ and $\mathrm{ABCG} 1$ is regulated by direct binding of liver X receptor (LXR) $(92,93)$. Administration of synthetic LXR agonists has been reported to successfully attenuate atherosclerotic development (94). However, systemic administration of LXR ligands causes unfavorable effects, including liver steatosis and hypertriglyceridemia due to activation of enzymes associated with fatty acid biosynthesis (95-98). Therefore, several studies have attempted to discriminate the mechanisms of LXR activation between liver and macrophages. Kim et al (99) reported that thyroid hormone receptor-associated protein 80 (TRAP80) selectively activates LXR-mediated sterol regulatory element binding protein 1c, which causes liver steatosis, but not LXR-mediated ABCA1 expression. Combinatory treatments to concomitantly reduce TRAP80 activity and increase LXR activity could be of potential therapeutic use against atherosclerosis (99). Furthermore, nanotechnology has recently been employed for local delivery of LXR agonists to macrophages/foam cells without systemic effects $(100,101)$. The delivery of the LXR agonist GW3965 encapsulated in poly(lactide-co-glycoli de)-b-poly(ethylene glycol) copolymer nanoparticles to $\mathrm{LDLR}^{-1-}$ mice markedly reduced the number of macrophages and decreased the size of atherosclerotic plaques by $50 \%$, without increasing total cholesterol and TAG levels in liver and plasma (100). Alternatively, Lim et al (101) developed a 
novel site-specific antibody-drug conjugate (ADC) to target and deliver an aminooxy-modified LXR agonist conjugated to anti-CD11-immunoglobulin $\mathrm{G}$ through a stable, cathepsin B cleavable oxime linkage. The LXR agonist delivered by ADC was 3-fold more powerful than the conventional LXR agonist T0901317 when tested in THP-1 macrophages, but it did not induce LXR target genes in hepatocytes (101). However, the effect of this delivery system remains untested in vivo. Since targeted delivery of LXR agonists effectively prevents atherosclerosis while avoiding the unfavorable side effects of conventional LXR agonists, additional research in this field is strongly supported, and underscores the potential of nanomedicine to treat atherosclerotic cardiovascular disease.

\section{Conclusion}

Atherosclerosis is a life threatening pathology, which progresses as plaques grow in the arterial wall. Macrophages/foam cells are found in the plaques from the early to late stages of atherosclerotic development. Therefore, numerous efforts to elucidate the mechanisms underlying foam cell formation, and to target foam cells to prevent and/or reverse atherosclerosis have been made. Presumably, given the complexity of advanced plaques, effective interventions against atherosclerosis should involve several pathways. Recent advances concerning the mechanisms underlying foam cell formation have identified several LDAPs in macrophages. Genetic modulation of some of these proteins in mice has supported the hypothesis that LDAPs may represent plausible novel targets for the amelioration of atherogenesis by preventing foam cell formation, and promoting RCT with less side effects than other interventions on non-LD foam cell proteins. The recent identification of novel LDAPs in macrophages leaves much room for research on the role of these proteins in lipid homeostasis and the development of atherosclerosis. Unveiling the function of diverse LDAPs and elucidating their molecular network may lead to novel therapeutic strategies to overcome atherosclerosis.

\section{Acknowledgements}

The authors of the present study would like to acknowledge the support from the National Institutes of Health R01 Grant (grant no. HL104251; to A. Paul) and the American Heart Association Scientist Development Grant (grant no. 14SDG19690016; to Y. Goo).

\section{References}

1. Go AS, Mozaffarian D, Roger VL, Benjamin EJ, Berry JD, Borden WB, Bravata DM, Dai S, Ford ES, Fox CS, et al; American Heart Association Statistics Committee and Stroke Statisics: Executive summary: Heart disease and stroke statistics - 2013 update: A report from the American Heart Association. Circulation 127: 143-152, 2013.

2. Ross R: The pathogenesis of atherosclerosis: A perspective for the 1990s. Nature 362: 801-809, 1993.

3. Ross R, Glomset J and Harker L: Response to injury and atherogenesis. Am J Pathol 86: 675-684, 1977.

4. Williams KJ and Tabas I: The response-to-retention hypothesis of early atherogenesis. Arterioscler Thromb Vasc Biol 15 551-561, 1995.

5. Maxfield FR and van Meer G: Cholesterol, the central lipid of mammalian cells. Curr Opin Cell Biol 22: 422-429, 2010.
6. Maxfield FR and Tabas I: Role of cholesterol and lipid organization in disease. Nature 438: 612-621, 2005.

7. Walther TC and Farese RV Jr: The life of lipid droplets. Biochim Biophys Acta 1791: 459-466, 2009.

8. Thiam AR, Farese RV Jr and Walther TC: The biophysics and cell biology of lipid droplets. Nat Rev Mol Cell Biol 14: 775-786, 2013.

9. Liu P, Ying Y, Zhao Y, Mundy DI, Zhu M and Anderson RG: Chinese hamster ovary K2 cell lipid droplets appear to be metabolic organelles involved in membrane traffic. J Biol Chem 279: 3787-3792, 2004.

10. Umlauf E, Csaszar E, Moertelmaier M, Schuetz GJ, Parton RG and Prohaska R: Association of stomatin with lipid bodies. J Biol Chem 279: 23699-23709, 2004.

11. Kusminski CM, Shetty S, Orci L, Unger RH and Scherer PE: Diabetes and apoptosis: Lipotoxicity. Apoptosis 14: 1484-1495, 2009.

12. Tabas I: Consequences of cellular cholesterol accumulation: Basic concepts and physiological implications. J Clin Invest 110: 905-911, 2002.

13. Herranz P, de Lucas R, Pérez-España L and Mayor M: Lipodystrophy syndromes. Dermatol Clin 26: 569-578, ix, 2008.

14. Bartz R, Li WH, Venables B, Zehmer JK, Roth MR, Welti R, Anderson RG, Liu P and Chapman KD: Lipidomics reveals that adiposomes store ether lipids and mediate phospholipid traffic. J Lipid Res 48: 837-847, 2007.

15. Buhman KF, Accad $M$ and Farese RV: Mammalian acyl-CoA:Cholesterol acyltransferases. Biochim Biophys Acta 1529: 142-154, 2000.

16. Yen CL, Stone SJ, Koliwad S, Harris C and Farese RV Jr: Thematic review series: Glycerolipids. DGAT enzymes and triacylglycerol biosynthesis. J Lipid Res 49: 2283-2301, 2008.

17. Robenek H, Hofnagel O, Buers I, Robenek MJ, Troyer D and Severs NJ: Adipophilin-enriched domains in the ER membrane are sites of lipid droplet biogenesis. J Cell Sci 119: 4215-4224, 2006.

18. Robenek MJ, Severs NJ, Schlattmann K, Plenz G, Zimmer KP, Troyer D and Robenek H: Lipids partition caveolin-1 from ER membranes into lipid droplets: Updating the model of lipid droplet biogenesis. FASEB J 18: 866-868, 2004.

19. Tauchi-Sato K, Ozeki S, Houjou T, Taguchi R and Fujimoto T: The surface of lipid droplets is a phospholipid monolayer with a unique fatty acid composition. J Biol Chem 277: 44507-44512, 2002.

20. Ozeki S, Cheng J, Tauchi-Sato K, Hatano N, Taniguchi H and Fujimoto T: Rab18 localizes to lipid droplets and induces their close apposition to the endoplasmic reticulum-derived membrane. J Cell Sci 118: 2601-2611, 2005.

21. Long AP, Manneschmidt AK, VerBrugge B, Dortch MR, Minkin SC, Prater KE, Biggerstaff JP, Dunlap JR and Dalhaimer P: Lipid droplet de novo formation and fission are linked to the cell cycle in fission yeast. Traffic 13: 705-714, 2012.

22. Yuan Y, Li P and Ye J: Lipid homeostasis and the formation of macrophage-derived foam cells in atherosclerosis. Protein Cell 3: 173-181, 2012.

23. Goo YH, Son SH, Kreienberg PB and Paul A: Novel lipid droplet-associated serine hydrolase regulates macrophage cholesterol mobilization. Arterioscler Thromb Vasc Biol 34: 386-396, 2014.

24. Brasaemle DL, Dolios G, Shapiro L and Wang R: Proteomic analysis of proteins associated with lipid droplets of basal and lipolytically stimulated 3T3-L1 adipocytes. J Biol Chem 279: 46835-46842, 2004.

25. Brasaemle DL: Thematic review series: Adipocyte biology. The perilipin family of structural lipid droplet proteins: Stabilization of lipid droplets and control of lipolysis. J Lipid Res 48: 2547-2559, 2007.

26. Greenberg AS,Egan JJ,Wek SA, Garty NB,Blanchette-MackieEJ and Londos C: Perilipin, a major hormonally regulated adipocyte-specific phosphoprotein associated with the periphery of lipid storage droplets. J Biol Chem 266: 11341-11346, 1991.

27. Servetnick DA, Brasaemle DL, Gruia-Gray J, Kimmel AR, Wolff J and Londos C: Perilipins are associated with cholesteryl ester droplets in steroidogenic adrenal cortical and Leydig cells. J Biol Chem 270: 16970-16973, 1995.

28. Zhao X, Gao M, He J, Zou L, Lyu Y, Zhang L, Geng B, Liu G and Xu G: Perilipin1 deficiency in whole body or bone marrow-derived cells attenuates lesions in atherosclerosis-prone mice. PLoS One 10: e0123738, 2015. 
29. Paul A, Chang BH, Li L, Yechoor VK and Chan L: Deficiency of adipose differentiation-related protein impairs foam cell formation and protects against atherosclerosis. Circ Res 102: $1492-1501,2008$

30. Lu X, Gruia-Gray J, Copeland NG, Gilbert DJ, Jenkins NA, Londos C and Kimmel AR: The murine perilipin gene: The lipid droplet-associated perilipins derive from tissue-specific, mRNA splice variants and define a gene family of ancient origin. Mamm Genome 12: 741-749, 2001.

31. Tansey JT, Huml AM, Vogt R, Davis KE, Jones JM, Fraser KA, Brasaemle DL, Kimmel AR and Londos C: Functional studies on native and mutated forms of perilipins. A role in protein kinase A-mediated lipolysis of triacylglycerols. J Biol Chem 278 : 8401-8406, 2003.

32. Zimmermann R, Strauss JG, Haemmerle G, Schoiswohl G Birner-Gruenberger R, Riederer M, Lass A, Neuberger G, Eisenhaber F, Hermetter A and Zechner R: Fat mobilization in adipose tissue is promoted by adipose triglyceride lipase. Science 306: 1383-1386, 2004.

33. Heid HW, Moll R, Schwetlick I, Rackwitz HR and Keenan TW: Adipophilin is a specific marker of lipid accumulation in diverse cell types and diseases. Cell Tissue Res 294: 309-321, 1998.

34. Dalen KT, Dahl T, Holter E, Arntsen B, Londos C, Sztalryd C and Nebb HI: LSDP5 is a PAT protein specifically expressed in fatty acid oxidizing tissues. Biochim Biophys Acta 1771: 210-227, 2007.

35. Becker L, Gharib SA, Irwin AD, Wijsman E, Vaisar T, Oram JF and Heinecke JW: A macrophage sterol-responsive network linked to atherogenesis. Cell Metab 11: 125-135, 2010.

36. Jiang HP and Serrero G: Isolation and characterization of a full-length cDNA coding for an adipose differentiation-related protein. Proc Natl Acad Sci USA 89: 7856-7860, 1992.

37. Masuda Y, Itabe H, Odaki M, Hama K, Fujimoto Y, Mori M, Sasabe N, Aoki J, Arai H and Takano T: ADRP/adipophilin is degraded through the proteasome-dependent pathway during regression of lipid-storing cells. J Lipid Res 47: 87-98, 2006.

38. Xu G, Sztalryd C, Lu X, Tansey JT, Gan J, Dorward H, Kimmel AR and Londos C: Post-translational regulation of adipose differentiation-related protein by the ubiquitin/proteasome pathway. J Biol Chem 280: 42841-42847, 2005.

39. Listenberger LL, Ostermeyer-Fay AG, Goldberg EB, Brown WJ and Brown DA: Adipocyte differentiation-related protein reduces the lipid droplet association of adipose triglyceride lipase and slows triacylglycerol turnover. J Lipid Res 48: 2751-2761, 2007.

40. Magne J, Aminoff A, Perman Sundelin J, Mannila MN, Gustafsson P, Hultenby K, Wernerson A, Bauer G, Listenberger L, Neville MJ, et al: The minor allele of the missense polymorphism Ser251Pro in perilipin 2 (PLIN2) disrupts an $\alpha$-helix, affects lipolysis, and is associated with reduced plasma triglyceride concentration in humans. FASEB J 27: 3090-3099, 2013.

41. Wolins NE, Skinner JR, Schoenfish MJ, Tzekov A, Bensch KG and Bickel PE: Adipocyte protein S3-12 coats nascent lipid droplets. J Biol Chem 278: 37713-37721, 2003.

42. Diaz E and Pfeffer SR: TIP47: A cargo selection device for mannose 6-phosphate receptor trafficking. Cell 93: 433-443, 1998.

43. Barbero P, Buell E, Zulley S and Pfeffer SR: TIP47 is not a component of lipid droplets. J Biol Chem 276: 24348-24351, 2001.

44. Miura S, Gan JW, Brzostowski J, Parisi MJ, Schultz CJ, Londos C, Oliver B and Kimmel AR: Functional conservation for lipid storage droplet association among Perilipin, ADRP and TIP47 (PAT)-related proteins in mammals, Drosophila and Dictyostelium. J Biol Chem 277: 32253-32257, 2002.

45. Buers I, Robenek H, Lorkowski S, Nitschke Y, Severs NJ and Hofnagel O: TIP47, a lipid cargo protein involved in macrophage triglyceride metabolism. Arterioscler Thromb Vasc Biol 29 . 767-773, 2009

46. Chang BH, Li L, Paul A, Taniguchi S, Nannegari V, Heird WC and Chan L: Protection against fatty liver but normal adipogenesis in mice lacking adipose differentiation-related protein. Mol Cell Biol 26: 1063-1076, 2006.

47. Wolins NE, Quaynor BK, Skinner JR, Tzekov A, Croce MA, Gropler MC, Varma V, Yao-Borengasser A, Rasouli N, Kern PA, Finck BN and Bickel PE: OXPAT/PAT-1 is a PPAR-induced lipid droplet protein that promotes fatty acid utilization. Diabetes 55: 3418-3428, 2006.

48. Li H, Song Y, Li F, Zhang L, Gu Y, Zhang L, Jiang L, Dong W, Ye $\mathrm{J}$ and $\mathrm{Li}$ Q: Identification of lipid droplet-associated proteins in the formation of macrophage-derived foam cells using microarrays. Int J Mol Med 26: 231-239, 2010.
49. Zhou Z, Yon Toh S, Chen Z, Guo K, Ng CP, Ponniah S, Lin SC, Hong $\mathrm{W}$ and Li P: Cidea-deficient mice have lean phenotype and are resistant to obesity. Nat Genet 35: 49-56, 2003.

50. Li JZ, Ye J, Xue B, Qi J, Zhang J, Zhou Z, Li Q, Wen Z and Li P: Cideb regulates diet-induced obesity, liver steatosis and insulin sensitivity by controlling lipogenesis and fatty acid oxidation. Diabetes 56: 2523-2532, 2007.

51. Toh SY, Gong J, Du G, Li JZ, Yang S, Ye J, Yao H, Zhang Y, Xue B, Li Q, et al: Up-regulation of mitochondrial activity and acquirement of brown adipose tissue-like property in the white adipose tissue of fsp27 deficient mice. PLoS One 3: e2890, 2008

52. Nishino N, Tamori Y, Tateya S, Kawaguchi T, Shibakusa T, Mizunoya W, Inoue K, Kitazawa R, Kitazawa S, Matsuki Y, et al: FSP27 contributes to efficient energy storage in murine white adipocytes by promoting the formation of unilocular lipid droplets. J Clin Invest 118: 2808-2821, 2008.

53. Gong J, Sun Z and Li P: CIDE proteins and metabolic disorders. Curr Opin Lipidol 20: 121-126, 2009.

54. Yeaman SJ: Hormone-sensitive lipase-a multipurpose enzyme in lipid metabolism. Biochim Biophys Acta 1052: 128-132, 1990.

55. Kraemer FB and Shen WJ: Hormone-sensitive lipase: Control of intracellular tri-(di-)acylglycerol and cholesteryl ester hydrolysis. J Lipid Res 43: 1585-1594, 2002.

56. Moore KJ, Kunjathoor VV, Koehn SL, Manning JJ, Tseng AA, Silver JM, McKee M and Freeman MW: Loss of receptor-mediated lipid uptake via scavenger receptor A or CD36 pathways does not ameliorate atherosclerosis in hyperlipidemic mice. J Clin Invest 115: 2192-2201, 2005.

57. Moore KJ, Sheedy FJ and Fisher EA: Macrophages in atherosclerosis: A dynamic balance. Nat Rev Immunol 13: 709-721, 2013.

58. Ouimet M, Franklin V, Mak E, Liao X, Tabas I and Marcel YL: Autophagy regulates cholesterol efflux from macrophage foam cells via lysosomal acid lipase. Cell Metab 13: 655-667, 2011.

59. Goldstein JL, Ho YK, Basu SK and Brown MS: Binding site on macrophages that mediates uptake and degradation of acetylated low density lipoprotein, producing massive cholesterol deposition. Proc Natl Acad Sci USA 76: 333-337, 1979.

60. Kunjathoor VV, Febbraio M, Podrez EA, Moore KJ, Andersson L, Koehn S, Rhee JS, Silverstein R, Hoff HF and Freeman MW: Scavenger receptors class A-I/II and CD36 are the principal receptors responsible for the uptake of modified low density lipoprotein leading to lipid loading in macrophages. J Biol Chem 277: 49982-49988, 2002

61. Suzuki H, Kurihara Y, Takeya M, Kamada N, Kataoka M, Jishage K, Ueda O, Sakaguchi H, Higashi T, Suzuki T, et al: A role for macrophage scavenger receptors in atherosclerosis and susceptibility to infection. Nature 386: 292-296, 1997.

62. Febbraio M, Podrez EA, Smith JD, Hajjar DP, Hazen SL, Hoff HF, Sharma K and Silverstein RL: Targeted disruption of the class B scavenger receptor $\mathrm{CD} 36$ protects against atherosclerotic lesion development in mice. J Clin Invest 105: 1049-1056, 2000.

63. Mäkinen PI, Lappalainen JP, Heinonen SE, Leppänen P, Lähteenvuo MT, Aarnio JV, Heikkilä J, Turunen MP and Ylä-Herttuala S: Silencing of either SR-A or CD36 reduces atherosclerosis in hyperlipidaemic mice and reveals reciprocal upregulation of these receptors. Cardiovasc Res 88: 530-538, 2010.

64. Manning-Tobin JJ, Moore KJ, Seimon TA, Bell SA, Sharuk M, Alvarez-Leite JI, de Winther MP, Tabas I and Freeman MW: Loss of SR-A and CD36 activity reduces atherosclerotic lesion complexity without abrogating foam cell formation in hyperlipidemic mice. Arterioscler Thromb Vasc Biol 29: 19-26, 2009.

65. Accad M, Smith SJ, Newland DL, Sanan DA, King LE Jr, Linton MF, Fazio S and Farese RV Jr: Massive xanthomatosis and altered composition of atherosclerotic lesions in hyperlipidemic mice lacking acyl CoA:cholesterol acyltransferase 1. J Clin Invest 105: 711-719, 2000.

66. Fazio S, Major AS, Swift LL, Gleaves LA, Accad M, Linton MF and Farese RV Jr: Increased atherosclerosis in LDL receptor-null mice lacking ACAT1 in macrophages. J Clin Invest 107: 163-171, 2001.

67. Warner GJ, Stoudt G, Bamberger M, Johnson WJ and Rothblat GH: Cell toxicity induced by inhibition of acyl coenzyme A:cholesterol acyltransferase and accumulation of unesterified cholesterol. J Biol Chem 270: 5772-5778, 1995.

68. Larigauderie G, Furman C, Jaye M, Lasselin C, Copin C, Fruchart JC, Castro G and Rouis M: Adipophilin enhances lipid accumulation and prevents lipid efflux from THP-1 macrophages: Potential role in atherogenesis. Arterioscler Thromb Vasc Biol 24: 504-510, 2004 
69. Nuotio K, Isoviita PM, Saksi J, Ijäs P, Pitkäniemi J, Sonninen R, Soinne L, Saimanen E, Salonen O, Kovanen PT, et al: Adipophilin expression is increased in symptomatic carotid atherosclerosis: Correlation with red blood cells and cholesterol crystals. Stroke 38: 1791-1798, 2007.

70. Son SH, Goo YH, Chang BH and Paul A: Perilipin 2 (PLIN2)-deficiency does not increase cholesterol-induced toxicity in macrophages. PLoS One 7: e33063, 2012.

71. Chen FL, Yang ZH, Wang XC, Liu Y, Yang YH, Li LX, Liang WC, Zhou WB and Hu RM: Adipophilin affects the expression of TNF-alpha, MCP-1 and IL-6 in THP-1 macrophages. Mol Cell Biochem 337: 193-199, 2010.

72.Langlois D, Forcheron F, Li JY, del Carmine P, Neggazi S and Beylot M: Increased atherosclerosis in mice deficient in perilipin1. Lipids Health Dis 10: 169, 2011.

73. Li JZ, Lei Y, Wang Y, Zhang Y, Ye J, Xia X, Pan X and Li P. Control of cholesterol biosynthesis, uptake and storage in hepatocytes by Cideb. Biochim Biophys Acta 1801: 577-586, 2010.

74. Brown AJ and Jessup W: Oxysterols and atherosclerosis. Atherosclerosis 142: 1-28, 1999.

75. Ishii I, Oka M, Katto N, Shirai K, Saito Y and Hirose S: Beta-VLDL-induced cholesterol ester deposition in macrophages may be regulated by neutral cholesterol esterase activity. Arterioscler Thromb 12: 1139-1145, 1992.

76. Kritharides L, Christian A, Stoudt G, Morel D and Rothblat GH: Cholesterol metabolism and efflux in human THP-1 macrophages. Arterioscler Thromb Vasc Biol 18: 1589-1599, 1998.

77. Escary JL, Choy HA, Reue K and Schotz MC: Hormone-sensitive lipase overexpression increases cholesteryl ester hydrolysis in macrophage foam cells. Arterioscler Thromb Vasc Biol 18 991-998, 1998.

78. Buchebner M, Pfeifer T, Rathke N, Chandak PG, Lass A, Schreiber R, Kratzer A, Zimmermann R, Sattler W, Koefeler H,et al: Cholesteryl ester hydrolase activity is abolished in HSL-/- macrophages but unchanged in macrophages lacking KIAA1363. J Lipid Res 51: 2896-2908, 2010.

79. Sekiya M, Osuga J, Nagashima S, Ohshiro T, Igarashi M, Okazaki H, Takahashi M, Tazoe F, Wada T, Ohta K, et al: Ablation of neutral cholesterol ester hydrolase 1 accelerates atherosclerosis. Cell Metab 10: 219-228, 2009.

80.Escary JL, Choy HA, Reue K, Wang XP, Castellani LW, Glass CK, Lusis AJ and Schotz MC: Paradoxical effect on atherosclerosis of hormone-sensitive lipase overexpression in macrophages. J Lipid Res 40: 397-404, 1999.

81. Choy HA, Wang XP and Schotz MC: Reduced atherosclerosis in hormone-sensitive lipase transgenic mice overexpressing cholesterol acceptors. Biochim Biophys Acta 1634: 76-85, 2003

82. Rothblat GH, de la Llera-Moya M, Atger V, Kellner-Weibel G, Williams DL and Phillips MC: Cell cholesterol efflux: Integration of old and new observations provides new insights. J Lipid Res 40: 781-796, 1999.

83. Allahverdian S, Pannu PS and Francis GA: Contribution of monocyte-derived macrophages and smooth muscle cells to arterial foam cell formation. Cardiovasc Res 95: 165-172, 2012.

84. Wang N, Lan D, Chen W, Matsuura F and Tall AR: ATP-binding cassette transporters G1 and G4 mediate cellular cholesterol efflux to high-density lipoproteins. Proc Natl Acad Sci USA 101: 9774-9779, 2004

85. van Eck M, Bos IS, Kaminski WE, Orsó E, Rothe G, Twisk J, Böttcher A, Van Amersfoort ES, Christiansen-Weber TA, Fung-Leung WP, et al: Leukocyte ABCA1 controls susceptibility to atherosclerosis and macrophage recruitment into tissues. Proc Natl Acad Sci USA 99: 6298-6303, 2002.

86. Singaraja RR, Fievet C, Castro G, James ER, Hennuyer N, Clee SM, Bissada N, Choy JC, Fruchart JC, McManus BM, et al: Increased ABCA1 activity protects against atherosclerosis. J Clin Invest 110: 35-42, 2002.
87. Burgess B, Naus K, Chan J, Hirsch-Reinshagen V, Tansley G Matzke L, Chan B, Wilkinson A, Fan J, Donkin J, et al: Overexpression of human ABCG1 does not affect atherosclerosis in fat-fed ApoE-deficient mice. Arterioscler Thromb Vasc Biol 28: 1731-1737, 2008.

88. Basso F, Amar MJ, Wagner EM, Vaisman B, Paigen B, Santamarina-Fojo S and Remaley AT: Enhanced ABCG1 expression increases atherosclerosis in LDLr-KO mice on a western diet. Biochem Biophys Res Commun 351: 398-404, 2006.

89. Baldán A, Pei L, Lee R, Tarr P, Tangirala RK, Weinstein MM, Frank J, Li AC, Tontonoz P and Edwards PA: Impaired development of atherosclerosis in hyperlipidemic Ldlr-/- and ApoE-/- mice transplanted with Abcg1-/- bone marrow. Arterioscler Thromb Vasc Biol 26: 2301-2307, 2006.

90. Out R, Hoekstra M, Hildebrand RB, Kruit JK, Meurs I, Li Z, Kuipers F, Van Berkel TJ and Van Eck M: Macrophage ABCG1 deletion disrupts lipid homeostasis in alveolar macrophages and moderately influences atherosclerotic lesion development in LDL receptor-deficient mice. Arterioscler Thromb Vasc Biol 26: 2295-2300, 2006.

91. Yvan-Charvet L, Ranalletta M, Wang N, Han S, Terasaka N, Li R, Welch C and Tall AR: Combined deficiency of ABCA1 and ABCG1 promotes foam cell accumulation and accelerates atherosclerosis in mice. J Clin Invest 117: 3900-3908, 2007.

92. Sabol SL, Brewer HB Jr and Santamarina-Fojo S: The human ABCG1 gene: Identification of LXR response elements that modulate expression in macrophages and liver. J Lipid Res 46: 2151-2167, 2005

93. Chawla A, Boisvert WA, Lee CH, Laffitte BA, Barak Y, Joseph SB, Liao D, Nagy L, Edwards PA, Curtiss LK, et al: A PPAR gamma-LXR-ABCA1 pathway in macrophages is involved in cholesterol efflux and atherogenesis. Mol Cell 7: 161-171, 2001

94. Calkin AC and Tontonoz P: Liver $\mathrm{x}$ receptor signaling pathways and atherosclerosis. Arterioscler Thromb Vasc Biol 30: $1513-1518,2010$

95. Magana MM and Osborne TF: Two tandem binding sites for sterol regulatory element binding proteins are required for sterol regulation of fatty-acid synthase promoter. J Biol Chem 271: 32689-32694, 1996

96. Magana MM, Lin SS, Dooley KA and Osborne TF: Sterol regulation of acetyl coenzyme A carboxylase promoter requires two interdependent binding sites for sterol regulatory element binding proteins. J Lipid Res 38: 1630-1638, 1997.

97. Foretz M, Pacot C, Dugail I, Lemarchand P, Guichard C, Le Lièpvre $\mathrm{X}$, Berthelier-Lubrano $\mathrm{C}$, Spiegelman $\mathrm{B}, \mathrm{Kim} \mathrm{JB}$ Ferré $\mathrm{P}$ and Foufelle F: ADD1/SREBP-1c is required in the activation of hepatic lipogenic gene expression by glucose. Mol Cell Biol 19: 3760-3768, 1999.

98. Cha JY and Repa JJ: The liver X receptor (LXR) and hepatic lipogenesis. The carbohydrate-response element-binding protein is a target gene of LXR. J Biol Chem 282: 743-751, 2007.

99. Kim GH, Oh GS, Yoon J, Lee GG, Lee KU and Kim SW: Hepatic TRAP80 selectively regulates lipogenic activity of liver X receptor. J Clin Invest 125: 183-193, 2015.

100.Zhang XQ, Even-Or O, Xu X, van Rosmalen M, Lim L, Gadde S, Farokhzad OC and Fisher EA: Nanoparticles containing a liver $\mathrm{X}$ receptor agonist inhibit inflammation and atherosclerosis. Adv Healthc Mater 4: 228-236, 2015.

101. Lim RK, Yu S, Cheng B, Li S, Kim NJ, Cao Y, Chi V, Kim JY, Chatterjee AK, Schultz PG, et al: Targeted delivery of LXR agonist using a site-specific antibody-drug conjugate. Bioconjug Chem 26: 2216-2222, 2015. 